\title{
Falares e aspectos culturais de Rondônia: a importância dos estudos sociolinguísticos, fonéticos e dialetológicos
}

Iara Maria TELES *

Resumo: Objetiva-se, neste artigo, fazer um rápido survol conceitual sobre Sociolinguística, Fonética e Dialetologia, visando a enfatizar a importância do conhecimento dos estudos desenvolvidos nessas áreas da Linguística para os profissionais que se ocupam do ensino do brasileiro. Na pesquisa que está sendo desenvolvida no Campus de Guajará-Mirim da Universidade Federal de Rondônia para a elaboração do Atlas Linguístico de Rondônia - ALiRO, fala-se em "falares" rondonienses e não "dialetos" e mostra-se que essa opção pelo termo "falares" está ligada às origens da população de Rondônia. Essa pesquisa pretende não só identificar as diferenças diatópicas consideradas no panorama da Geolinguística, mas, também, identificar os substratos culturais atuantes na constituição da cultura cosmopolita rondoniense para tentar responder à pergunta: Será que se pode dizer que o Estado de Rondônia possui um "falar" próprio? E o que dizer de sua cultura?

Palavras-chave: Dialetologia; Atlas linguístico; "Falares" de Rondônia.

Abstract: The intention of this article is do a quickly conceptual survol about sociolinguistic, phonetic, and dialectology, trying to emphasize the importance of the knowledge from studies in this

* Doutorado em Linguística pela Universidade Federal de Santa Catarina (1995). Docente da Universidade Federal de Rondônia. Contato: itelles18@gmail.com. 
area, to professionals that occupy on Brazilian education. In the research that is being developed in Guajara-Mirim's Campus of the Rondonia's Federal University to elaborate the Rondonia's ALIRO, it's shown that It's spoken in Rondonia's and not dialect and it's shown also that this option by the term speaking is connected to the origins of the population. This research claims not only identify diatopics differences considered in Geolinguistic view, but also identify cultural subtracts actuate in the Rondonia's cosmopolite cultural constitution trying answer the question: May we say that Rondonia's state has an own speaking? And what to say about its culture?

Keywords: Dialectology; Linguistic Atlas; Speaking' Rondonia

\section{Introdução}

Para falar da importância dos estudos sociolinguísticos, fonéticos e dialetológicos em nossos dias, seria interessante reportar aos primórdios da Linguística, no início do séc. XX, em que não se fazia a distinção entre Fonética e Fonologia, por exemplo. É notório que um dos fatos que contribuiu para a evolução da Linguística moderna foi a separação entre o que é fonético e o que é fonológico em um sistema linguístico, feita por Trubetzkoy (1933), que, então, distingue a Fonética da Fonologia, atribuindo àquela a descoberta do que de fato se pronuncia ao falar uma língua, e a esta, o que se crê pronunciar. A partir de então, várias áreas da Linguística foram se firmando e adquirindo independência como Fonética, Fonologia, Morfologia, Sintaxe e Semântica. Mais recentemente, vemos surgir a Pragmática, a Análise do Discurso, a Sociolinguística e outras mais.

O surgimento da Sociolinguística se deu com a publicação, em 1972, de Padrões sociolingüísticos [Sociolinguistic Patterns] de William Labov. Uma nova área dos estudos da linguagem não tem parado de se desenvolver em todo o mundo: a Sociolinguística Variacionista ou Sociolinguistica Quantitativa. Labov, ao trabalhar com mudança linguística, acaba descobrindo a complexa relação entre a diacronia 
- mudança - e a sincronia - variação linguística. Suas pesquisas constatam que as línguas mudam porque variam, porque não existem "línguas": existem falantes reais que vivem em sociedades complexas, hierarquizadas, heterogêneas, e que, eles sim, mudam as línguas - o que torna impossível desvincular os fatos de linguagem dos fatos sociais. Ao estudar a língua, os contextos socioculturais em que ela ocorre são elementos básicos e, muitas vezes, determinantes de suas variações, explicando e justificando fatos que apenas linguisticamente seriam difíceis ou até impossíveis de serem determinados.

Por outro lado, não se concebe o estudo do "falar" de uma comunidade isolado de sua cultura, pois, na concepção de Ferrarezi (2008) sobre língua, com a qual concordo, "Uma língua natural é um sistema socializado e culturalmente determinado de representação de mundos e seus eventos." E como toda língua natural é sujeita a variações e mudanças, imprescindível é o conhecimento da realidade local, sobretudo quando se considera o ensino do brasileiro. ${ }^{1} \mathrm{O}$ conceito de língua adotado por Ferrarezi Jr. (2007), não tem como fundamento apenas a estrutura e a etimologia dessa língua, mas, como já disse acima, "não privilegia a estrutura, mas o funcionamento representativo da língua inserida em uma cultura." (FERRAREZI Jr, 2007), o que permite uma compreensão mais ampla do que seja uma língua natural em funcionamento efetivo e permite considerar que uma língua é mais do que aquilo que é abrangido por uma circunscrição gramatical.

No século XIX, em determinado momento histórico, em que havia um isolamento geográfico das comunidades de falantes devido a fatores vários, tais como dificuldades de comunicação por meios rodoviários e, sobretudo, tecnológicos que permitissem

\footnotetext{
${ }^{1}$ Justifico, aqui, o emprego do termo "brasileiro" e não "português do Brasil", pois, sendo co-autora com Ferrarezi Jr. da obra Gramática do Brasileiro: uma nova forma de entender a nossa lingua, publicada pela Editora Globo, em 2008, coerentemente, não poderei me referir a "português do Brasil".
} 
a interação à distância entre as diversas regiões, corria-se o risco da extinção de dados, não de toda a língua, obviamente, que permitem a documentação dos diferentes estágios da língua. Essa foi uma das causas do surgimento dos estudos dialetológicos, a Dialetologia, hoje considerada ciência, com suas pesquisas baseadas em pressupostos da Geografia Linguística. Já afirmava o Abade Rousselot:

Chaque année qui s'écoule emporte avec elle des sons, des constructions, des mots dont la perte est irréparable. Il faut donc se hâter de sauver ce qui a été épargné jusqu'ici. C’est une oeuvre qui intéresse la science et l'honneur du pays. Plusieurs l'ont senti, et les ouvrages sur les patois se sont multipliés. On doit rendre hommage à ces patriotiques efforts, ainsi qu'aux pouvoirs publics et aux sociétés savants qui les ont encouragés et soutenus. Mais, il faut bien reconnaitre, ce qui a été fait est bien peu en comparaison de ce qui reste à faire.

Além de Rousselot, a Dialetologia teve outros precursores tais como o dialetólogo italiano Ascoli (1829-1907), considerado aquele que deu o caráter de ciência aos estudos dialetológicos, e o linguista alemão Georg Wenker (1852-1911). Sabe-se, porém, que L'Atlas Linguistique de la France (1902-1910), de autoria do linguista suíço Jules Gilliéron (1845-1926), professor na École Pratique de Hautes Études de Paris, é considerado, com seu método da Geografia Linguística, um marco metodológico para as pesquisas dialetológicas.

Como estudar uma língua significa, entre outras coisas, tomar conhecimento de suas variedades, é necessário enveredar pelos caminhos da Sociolinguística, da Fonética e da Dialetologia que, para Dubois (1971) é a descrição comparativa dos diferentes sistemas ou dialetos em que uma língua se diversifica no espaço, estabelecendo-lhe os limites. Seu campo de estudos é, consequentemente, os falares regionais com suas delimitações 
geográficas, caracterizadas por diferenças próprias na fonética, no léxico, na gramática...

Após esse rápido survol conceitual, julgamos desnecessário enfatizar a importância dos estudos sociolinguísticos, fonéticos e dialetológicos para os profissionais que se ocupam do ensino do brasileiro. Somente conhecendo a realidade linguística local é que poderão se posicionar face a conceitos linguísticos errôneos que aparecem nos manuais de ensino e levam a comportamentos preconceituosos quanto aos falares locais.

Nessa perspectiva, para colaborar com o ensino da língua materna, uma equipe de pesquisadores composta por doutores e mestres em Linguística do Campus de Guajará-Mirim e de Porto Velho da Universidade Federal de Rondônia e por um mestre em Linguística da Faculdade de Tecnologia e Ciências (FATEC) de Porto Velho está desenvolvendo dois projetos de pesquisa: um na área da Sociolinguística "Descrição sócio-histórica das vogais do brasileiro: falares rondonienses"; ${ }^{2}$ e outro para a elaboração do Atlas Linguístico de Rondônia - ALiRO, do que passaremos a tratar, ou melhor, antes disso, julgamos ser necessário responder às perguntas: (i) mas, afinal, o que é um atlas linguístico, e (ii) para que ele serve, ou seja, para que elaborá-lo?

Para Cunha (1984, p. 41), um atlas linguístico

É um grande vocabulário dialetal que visa a apresentar, de maneira científica e viva, sobre cada carta, as diferentes variantes de uma palavra ou de uma pequena frase em território mais ou menos vasto. Como as palavras e frases objetos da pesquisa são escolhidas previamente, depois de apurado estudo das formas culturais de uma comunidade de que a língua é a expressão -, o inventário, embora incompleto, torna possível ampla visão dos traços essenciais do vocabulário, sua repartição geográfica, sua vitalidade,

\footnotetext{
${ }^{2}$ Como ainda está em fase de realização das entrevistas de campo, não o relataremos neste artigo.
} 
história dos termos, viagens de palavras, evolução de formas gramaticais, diferenças de pronúncia, relações dos dialetos e falares com a língua culta. E, como a palavra está estreitamente ligada à coisa que designa, o Atlas permite também o aferimento da vivência de formas e complexos culturais.

Para Brandão (1991, p. 25), “Um Atlas lingüístico é o conjunto de mapas em que se registram os traços fonéticos, lexicais e/ou morfossintáticos característicos de uma língua num determinado âmbito geográfico.”

Compreende-se, pelas definições citadas, a necessidade de seguir os pressupostos teóricos da Geografia Linguística, que analisa as variantes linguísticas por meio de estudos cartográficos, para a elaboração de um atlas linguístico.

$\mathrm{Na}$ visão de Rasky, Lima e Oliveira (2006), a pesquisa linguística variacionista (fonética, morfossintaxe, léxico), a história da língua e a política linguística (política de ensino) são fortes argumentos que justificam a construção de um atlas linguístico, pois, por exemplo, ao demonstrar em um atlas os fatos fonéticos, morfossintáticos e lexicais de uma língua, que vão se modificando através dos tempos, contribui-se com o ensino da língua materna.

Veja-se pelo título deste artigo que nos referimos a "falares" rondonienses e não a dialetos, mesmo porque o conceito de dialeto é algo complicado em Linguística, que não cabe aqui analisar. Essa opção pelo termo "falares" está ligada às origens da população de Rondônia. Vejamos.

\section{Colonização de Rondônia: origens}

Rondônia é um Estado relativamente novo, pois a transformação do Território Federal de Rondônia em Estado deuse em dezembro de 1981 e somente três de seus 52 municípios foram criados antes de 1980: Porto Velho (1914), Guajará-Mirim (1928) e Vilhena (1977). 


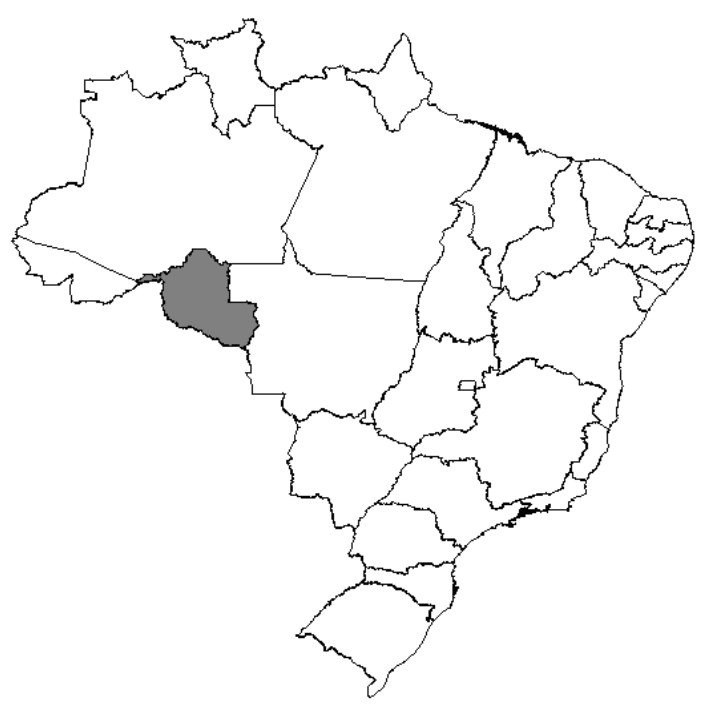

Figura 1 - Rondônia no Brasil

Revisitando a história rondoniense, constatou-se que missões jesuíticas do século XVII instalaram-se em alguns pontos do rio Madeira, na área ocupada atualmente pelo Estado de Rondônia.

Em 1776, deu-se a construção do Forte Príncipe da Beira devido à constante presença de tropas portuguesas na região para ocupar o vale do rio Guaporé, em virtude da descoberta de ouro em Cuiabá, em 1750.

Com a construção da Estrada de Ferro Madeira-Mamoré (EFMM), em 1917 , surgiram, nas extremidades dessa linha férrea, os dois primeiros povoados de Rondônia: Guajará-Mirim e Porto Velho, ${ }^{3}$ que pertenciam, respectivamente, ao Estado de Mato Grosso e ao Estado do Amazonas.

\footnotetext{
${ }^{3}$ A EFMM foi extinta em 1972, com a abertura da BR-425 ligando
} Guajará-Mirim a Porto Velho. 
Em 13 de setembro de 1943, foi criado o Território Federal do Guaporé, resultado do desmembramento dos Estados do Mato Grosso e do Amazonas, passando, então, Guajará-Mirim e Porto Velho a pertencer a essa nova Unidade da Federação até 17 de novembro de 1956, quando, então, o referido território foi transformado em Território Federal de Rondônia, em homenagem ao marechal Cândido Mariano da Silva Rondon, para, somente em 22 de dezembro de 1981, receber o status de Estado, como já foi dito acima.

Por ser o Estado de Rondônia, situado na Amazônia, um estado cosmopolita, o que o diferencia dos demais estados brasileiros no que tange à sua colonização, acredita-se ser este um dos grandes fatores que justificam a elaboração de seu atlas linguístico.

Por que se acredita que Rondônia é um estado cosmopolita? Pela história peculiar da formação de sua população (cerca de 1.534.594 habitantes distribuídos em 237.576,167 $\mathrm{Km}^{2}$ ), que, em seu início, deveu-se a pioneiros vindos das mais diversas regiões do Brasil, sobretudo do Nordeste, e aos estrangeiros atraídos por diversas razões: pela construção da Estrada de Ferro MadeiraMamoré, pela extração da borracha, pelo garimpo e, finalmente, pela agropecuária. Conheçamos, então, um pouco dessa história.

Por ser uma região de terras banhadas por rios caudalosos, a Amazônia começou a atrair o nordestino como um meio de fugir das secas de 1877, como assinalou Araújo Lima em sua obra Amazônia, a Terra e o Homem (apud SILVA, 1984). Além disso, diversos programas governamentais de ocupação da Amazônia foram desenvolvidos e esses tinham como populações-alvo os nordestinos da região da seca. Milhares de nordestinos foram "transferidos" de sua região de origem para regiões amazônicas, sob a justificativa da presença de água, mas, no fundo, com a intenção de ocupação das áreas antes apenas ocupadas por indígenas. Um processo semelhante se desenvolveu no estado do Acre.

Como se sabe, naquela época, o atual estado do Acre era território boliviano. Entretanto, a riqueza do Acre em borracha e 
madeira e a grande concentração de nordestinos incentivados pelo governo a ocupar aquelas terras deram início a um problema diplomático. Como a Bolívia, por aquela época, havia perdido, através de guerras contra Chile e Peru, as saídas para o Oceano Pacífico, era premente para aquele país encontrar uma saída para o mar através da Bacia Amazônica para o escoamento de sua produção extrativista. A saída mais óbvia era através do Rio Amazonas, que tem contato direto com o Atlântico e é todo navegável. Mas, o acesso ao Amazonas só era possível através dos Rios Mamoré e Madeira, que, por sua vez, não são navegáveis no trecho entre as atuais cidades de Guajará-Mirim e Porto Velho. Como o trecho encachoeirado desses rios impedia a navegação, Brasil e Bolívia vislumbram a possibilidade de um negócio internacional: o Acre, em troca de um pouco de dinheiro e da construção de uma estrada de ferro que cobrisse a área encachoeirada com Madeira, a qual completaria a ponte de escoamento da produção boliviana para os oceanos. Eis a origem da EFMM.

Nasceu, assim, a Madeira-Mamoré Railways Co. Ltda., que contratou, inicialmente, a execução da ferrovia com a firma de engenharia inglesa Public Works, que abandonou o "campo de batalha" logo no início. Deu sequência aos trabalhos a empresa americana P \& T Collins, que contratou trabalhadores norteamericanos, irlandeses, italianos e brasileiros. Devido às tragédias ocasionadas pelos ataques dos índios e pelas intempéries, doenças (malária, disenteria, beribéri e a pneumonia) e fauna da Amazônia, que dizimavam os trabalhadores (daí o nome de "ferrovia do diabo"), a construção da ferrovia foi interrompida em agosto de 1879 para ser retomada somente em 1907, pela empresa americana May-Jekyll e Rodolph, dirigida por Percival Farquar.

Com a retomada da obra da EFMM, foram contratados trabalhadores não só brasileiros, mas espanhóis, portugueses, alemães, antilhanos, colombianos, italianos, norte-americanos, bolivianos, franceses, russos, cubanos, mexicanos, indianos, ingleses, peruanos, suecos, belgas, húngaros e irlandeses (SILVA, 1984). Apesar das tragédias que continuaram (dizem que a cada 
dormente corresponde uma alma), a ferrovia foi concluída pela Madeira-Mamoré Railways Co. em 1917, consolidando-se, em suas extremidades, os dois primeiros povoados de Rondônia: GuajaráMirim e Porto Velho, cujo crescimento deveu-se a seringueiros, ao lado de ferroviários, membros da linha telegráfica de Rondon e extrativistas em geral.

Registre-se que aquela foi a época do auge da produção da borracha na área do Vale do Guaporé.

Mais recentemente, o mote responsável pela ocupação de Rondônia foi a construção da BR-364, na década de 60 , que propiciou a vinda de grande quantidade de migrantes de todas as partes do país, principalmente do Paraná, Espírito Santo, Santa Catarina e Minas Gerais.

Fator muito importante que veio contribuir, também, para o crescimento demográfico da região, paralelamente à BR-364, foi a exploração da cassiterita. Garimpeiros vinham, principalmente, do Maranhão, Piauí, Ceará, Goiás, Mato Grosso, Pará e Amazonas para explorar a grande fonte, à época, de riqueza da região.

Todos esses migrantes, quaisquer que fossem suas origens e intenções, acabaram deixando marcas na cultura local, o que inclui marcas linguísticas. Nesse caldo heterogêneo de culturas, começa a se formar a população tipicamente rondoniense: gerações de filhos de migrantes, que dão início, na década de 70 , à consolidação de traços culturais mais marcantes e de um linguajar um pouco mais definido, o qual, porém, não se repete em todos os municípios do Estado. Viajando por Porto Velho, por exemplo, tem-se, em determinados momentos, a impressão de estar num estado nordestino. Já em Ji-Paraná, Rolim de Moura, Cacoal ou Vilhena, a impressão é a de estar na Região Sul, mais propriamente no Paraná ou em Santa Catarina. E essas diferenças se multiplicam nos 52 municípios do Estado. Essa heterogeneidade precisa ser estudada, registrada e acompanhada em sua evolução através da importante investigação e descrição das histórias particulares dos diferentes grupos que vieram constituir este Estado brasileiro, de modo a aprofundar o conhecimento de sua identidade linguística e cultural, 
desmistificando a desvalorização das diversidades em favor dos padrões linguísticos homogêneos.

Tendo feito um breve percurso para situar a evolução de povoado a Estado de Rondônia, façamos um parênteses para conhecer as armas estaduais e seus significados.

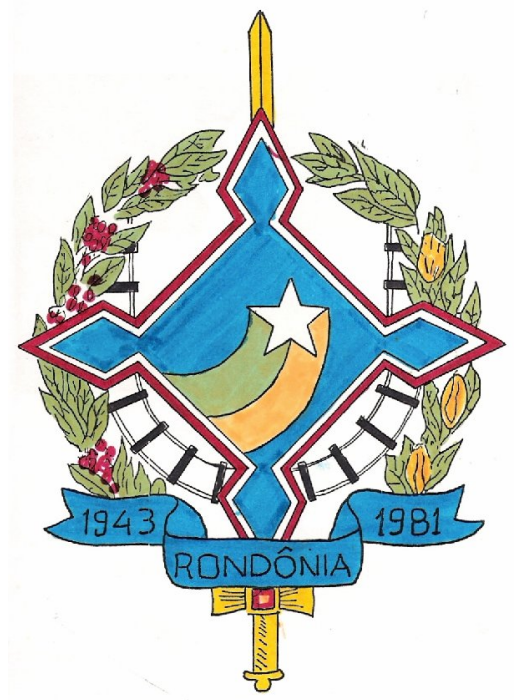

Figura 2 - Brasão do Estado de Rondônia

Em primeiro plano, estão as muralhas do Real Forte Príncipe da Beira, que repousam sobre uma espada. Como já vimos acima, as datas 1943 e 1981 representam, respectivamente, a criação do Território do Guaporé e do Estado de Rondônia. A EFMM está representada por um ramal ferroviário em forma de "U", cercado por um ramo de café, à esquerda, e um de cacau, à direita, produtos do Estado. Ao centro, uma estrela branca com cauda verde e amarela representa o novo Estado da Federação.

Pelo que foi exposto até aqui, chega-se ao objetivo da elaboração do Atlas Linguístico de Rondônia - ALiRO: descrever 
os diversos "falares" de Rondônia, por meio da investigação das histórias particulares dos diferentes grupos que vieram constituir este Estado brasileiro, para responder às perguntas: o Estado de Rondônia possui um "falar" próprio? E o que dizer de sua cultura? Esse último questionamento pode parecer muito amplo, mas o que pretendemos é não só identificar as diferenças diatópicas consideradas no panorama da Geolinguística, mas, também, os substratos culturais atuantes na constituição da cultura rondoniense. Da mesma forma, é importante a identificação da influência das línguas indígenas de Rondônia na formação do léxico dos "falares rondoniense".

Até o presente momento, ainda não foram descritas as variantes diatópicas do brasileiro falado em Rondônia. Há apenas duas dissertações, defendidas no Curso de Mestrado em Linguística do Campus de Guajará-Mirim, que atendem aos objetivos deste projeto: "Análise fonética de róticos falados por habitantes nativos da região urbana de Porto Velho" (CAPILÉ, 2004) e "A influência da migração no processo de aculturação do léxico de Porto Velho a partir de 1980" (OLIVEIRA, 2004). Na área de línguas indígenas, são várias as dissertações de Mestrado e teses de Doutorado defendidas.

É inegável a importância dos estudos dialetológicos e geolinguísticos, que têm sido e vêm se desenvolvendo no país, para que não "se percam de vez os fios que se foram soltando ao longo destes 500 anos" (AGUILERA, 2002, p. 89). Assim, as pesquisas que serão desenvolvidas para a elaboração do ALiRO e que, certamente, oferecerão um melhor conhecimento de todos os fatores linguístico-culturais que determinam o "falar rondoniense" virão somar-se ao universo das pesquisas dialetológicas e geolinguísticas, além de ser mais uma contribuição para a elaboração do Atlas Linguístico do Brasil (ALiB), pois, apesar de não estar diretamente ligado a esse projeto, certamente trará contribuições importantíssimas para a descrição do brasileiro e para futuros estudos comparativos com os resultados do ALiB. 


\section{Rede de inquéritos}

Dividimos Rondônia em três grandes regiões, de acordo com as influências recebidas de imigrantes e migrantes em sua colonização, e selecionamos 15 pontos de inquérito (PI) (12 municípios e 3 distritos) dentre os 52 municípos do Estado: Região Norte, Vale do Guaporé-Mamoré e Cone Sul.

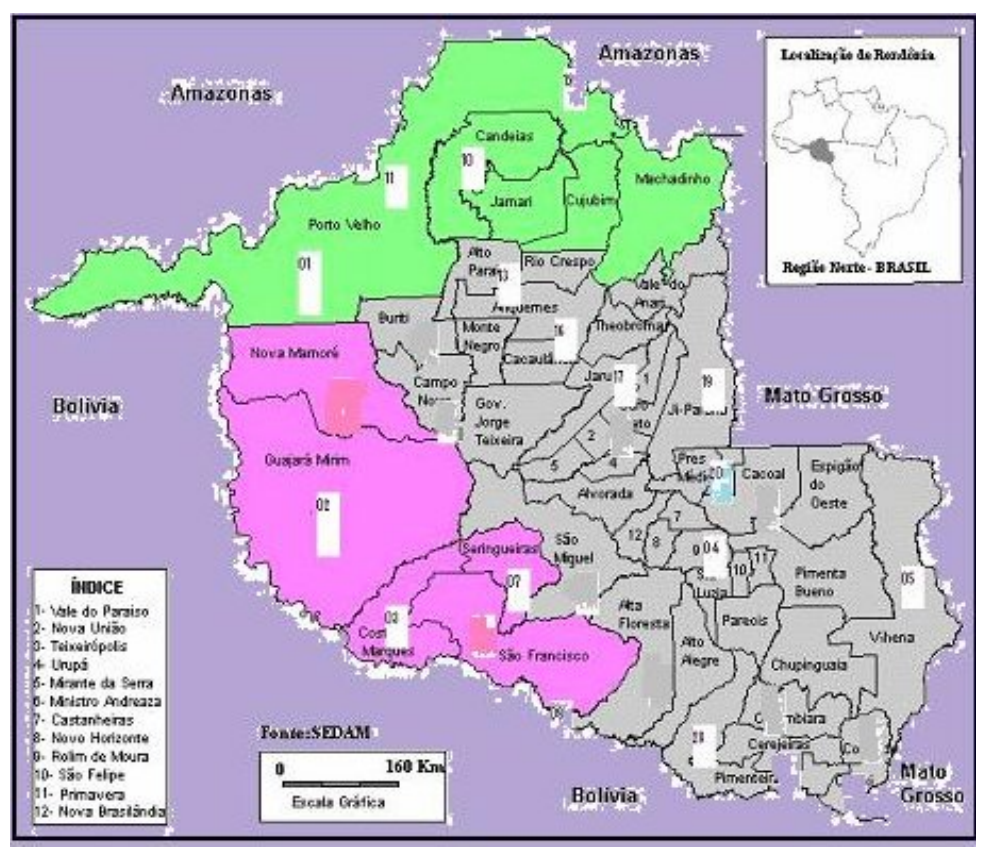

Figura 3 - Rede de pontos

1. Região Norte (cor verde) (4PI): influência de nordestinos, sobretudo do Ceará, e de amazonenses: PI 01 - Porto Velho, PI 02 - Candeias, PI 03 - São Carlos (distrito) e PI 04 Calama (distrito).

2. Vale do Guaporé-Mamoré (cor rosa) (4PI), região que se pode, aproximadamente, considerar como tendo um "falar" mais 
típico da terra: influência de gregos, libaneses, turcos, sírios, italianos, barbadianos, bolivianos, quilombolos, indígenas e nordestinos, sobretudo provenientes dos estados do Ceará, Bahia, Rio Grande do Norte e Paraíba: PI 05 - Guajará-Mirim, PI 06 Costa Marques, PI 07 - Seringueiras, e PI 08 - Pedras Negras (distrito).

3. Cone Sul (cor cinza) (7PI): influência de mato-grossenses, paulistas, paranaenses, catarinenses, gaúchos e, em menor escala, capixabas, mineiros e baianos: PI 09 - Alto Paraíso, PI 10 Ariquemes, PI 11 - Jaru, PI 12 - Ji-Paraná, PI 13 - Pimenta Bueno, PI 14 - Vilhena e PI 15 - Pimenteiras.

\section{Corpus e informantes}

O corpus para a análise linguística e elaboração do ALiRO está sendo constituído por meio de pesquisa direta e com a aplicação dos três questionários do ALiB (COMITÊ NACIONAL, 2001): 1) questionário fonético-fonológico (QFF);2) questionário semântico-lexical (QSL); 3) questionário morfossintático (QMS), além de questões de prosódia, de pragmática, metalinguísticas e das que propõem discursos semidirigidos.

Os dados estão sendo coletados com um gravador Digital Voice Recorder, marca Olympus VN240 e transferidos para PC com o aplicativo Digital Wave Player para Windows 98/2000/Me/XP, marca Olympus.

Para a seleção dos informantes, estão sendo observadas as variáveis definidas pelo Comitê Nacional do ALiB: naturalidade (deverão ser naturais da localidade pesquisada e filhos de pais também nascidos na região), faixa etária (faixa I, entre 18 e 30 anos, e faixa II, entre 50 e 65 anos), sexo (M e F) e escolaridade (alfabetizados, no máximo até a $8^{a}$ série), tendo em vista trabalhos comparativos posteriores.

Com a observância dessas variáveis, pode-se "atender às possibilidades de melhor confronto entre usos por diferentes faixas etárias e, também, propiciar a análise da variação e da mudança linguísticas", como enfatiza o Comitê Nacional do ALiB (2001). 
No entanto, não só pela história da formação da população de Rondônia, mas, também, por ser um Estado que possui apenas 2 (dois) municípios, Porto Velho e Guajará-Mirim, cuja criação se deu antes dos anos 40 , será quase impossível encontrar informantes em todos os PI que se enquadrem no perfil delineado. Assim, pelas características de sua criação e formação de sua população, o ALiRO não será um atlas nos moldes dos tradicionais, um atlas topoestático, mas, sim, um atlas topodinâmico, a exemplo do Atlas Linguístico Diatópico e Diastrático do Uruguai.

\section{Estado atual da pesquisa}

O corpus da pesquisa já foi quase que totalmente coletado, pois tínhamos previsto o término da coleta de dados em abril de 2009.

As entrevistas estão sendo transcritas pela equipe de pesquisadores, podendo-se, desde já, grosso modo, constatar as influências da grande migração em Rondônia.

Pretende-se a publicação do ALiRO, no formato digital, sob a supervisão dos doutores Vanderci de Andrade Aguilera, da Universidade Estadual de Londrina, e de Abdelhak Razky da Universidade Federal do Pará.

\section{À guisa de conclusão}

Reafirmamos que os atlas linguísticos servem para documentar e registrar a variação linguística local, detectando as características específicas e gerais dos diversos falares brasileiros, o que possibilita a definição de áreas dialetais, e que tudo isso é possível com a contribuição das pesquisas realizadas seguindo a orientação metodológica preconizada pela Dialetologia e pela Geografia Linguística. Necessário se faz, agora, salientar que essa contribuição se estende, também, ao ensino-aprendizagem de língua materna.

A partir do momento em que o professor conhece a variedade de fala local, informação fornecida pelos atlas linguísticos, 
deverá compreender, por exemplo, que muitas dificuldades ortográficas apresentadas por seus alunos são em decorrência dessa variedade: grafar mintiu por mentiu, tauba por tábua, grélha (acento na ortografia devido à pronúncia aberta encontrada em GuajaráMirim-RO) por grelha, etc.. Além da oralidade, o professor deve saber que há uma relação entre as dificuldades ortográficas e a Fonologia: como exemplo, cite-se o caso de 'pneu', com as dificuldades de ortografia e pronúncia, por não apresentar o brasileiro em sua fonotática a sequência $\mathrm{CV}$ em posição de onset; assim, tem-se a ortografia 'peneu' e a pronúncia [pi'new].

Almeja-se que o professor, sobretudo o alfabetizador, dispondo de informações que caracterizam maneiras diferentes de o falante nativo se comunicar, que muitas vezes são formas estigmatizadas mas não constituem erro, pois erro gramatical é só o que prejudica a compreensão, passe a refletir sobre sua prática educativa e não adote atitudes preconceituosas com relação a seus alunos. E, para que o professor não seja preconceituoso, é necessário que em sua formação haja um embasamento sociolinguístico.

Para concluir, o que se espera com o desenvolvimento do ALiRO é, antes de tudo, poder caracterizar, por meio da descrição de uma amostra das variantes linguísticas de Rondônia, o que é realmente falado nesse Estado. Mas espera-se, também, organizar um banco de dados que possa servir para pesquisas em todas as áreas da Linguística, a ser utilizado não só por pesquisadores da Universidade Federal de Rondônia, mas por todos os que se interessarem por tais pesquisas.

\section{Referências}

AGUILERA, Vanderci de Andrade. Os caminhos da dialetologia: os atlas lingüísticos do Brasil. In: HENRIQUES, Claudio Cezar; PEREIRA, Maria Teresa Gonçalves (Org.). Língua e transdisciplinaridade: rumos, conexões, sentido. São Paulo: Contexto, 2002. p. 77-92. 
BRANDÃO, Silvia Figueiredo. A geografia lingüística no Brasil. São Paulo: Ática, 1991.

CAPILÉ, Ângela Maria P. Análise fonética de róticos falados por habitantes nativos da região urbana de Porto Velho. 2004. Dissertação (Mestrado em Linguística) - Universidade Federal de Rondônia, Guajará-Mirim.

COMITÊ NACIONAL DO PROJETO ALiB. Atlas Lingüístico do Brasil: questionários 2001. Londrina: Eduel, 2001.

CUNHA, Celso. Língua portuguesa e realidade brasileira. Tempo Brasileiro, Rio de Janeiro, n. 13, 10. ed., 1984.

DUBOIS, Jean; DUBOIS, Claude. Introduction à la lexicographie. Le Dictionnaire. Paris: Larousse, 1971. (Col. Langue et Langage).

FERRAREZI JR., Celso. Introdução à Semântica de contextos e cenários. São Paulo: Mercado de Letras, 2008.

Ensinar o brasileiro: respostas a perguntas de professores de língua materna. São Paulo: Parábola, 2007.

OLIVEIRA, João José de A influência da migração no processo de aculturação do léxico de Porto Velho a partir de 1980. 2004. Dissertação (Mestrado em Linguística) - Universidade Federal de Rondônia, Guajará-Mirim.

RAZKY, Abdelhak; LIMA, Alcides; OLIVEIRA, Marilúcia. Atlas lingüísticos: contribuição para o ensino básico. In: MOTA, Jacyra Andrade; CARDOSO, Suzana Alice Marcelino (Orgs.) Projeto Atlas Lingüístico do Brasil. Salvador: Quarteto, 2006. p. 109126.

SILVA, Amizael Gomes da. No rastro dos Pioneiros: um pouco da história rondoniana. Porto Velho: Escopo, 1984. 
TRUBETZKOY, Nikolay. A fonologia atual. In: DASCAL, Marcelo. Fundamentos metodológicos da Linguística. v. II. Fonologia e Sintaxe. 1981. 